\title{
ECONOMÍA BIDIMENSIONAL
}

\author{
DOS PARADIGMAS DE META-ECONOMÍA COMPARADOS: \\ EL ANDINO-TRADICIONAL Y EL CRISTIANO-MEDIEVAL
}

Juan van Kessel ${ }^{I}$

\begin{abstract}
RESUMEN
La mística cristiana medieval y la correspondiente 'Economía de la Salud' son comparadas con la cosmovisión (o 'Pacha-vivencia') andina y la correspondiente 'economía de crianza'. Se demuestra la afinidad del paradigma cristiano medieval de la Economía Sacramental de la Salud -ESS, y del paradigma andino de la Economía de Crianza de la Vida - ECV.
\end{abstract}

\section{Hipótesis}

1. Se reconoce una estructura similar (entre la teología y la mística cristiana medieval, por un lado, y la mitología y la Pacha-vivencia andina contemporánea por otro) cuando hacemos un análisis comparativo entre:

- La fe en el Corpus Christi Mysticum que es la matriz de la Economía Sacramental de la Salud - ESS, y

- La fe en la Pachamama que es la matriz de la Economía de Crianza de la Vida -ECV.

2. Esto es válido tanto por el concepto de la economía global (como mega-sistema único), como también por el esfuerzo individual del cristiano en su vida ética y litúrgica con que crea su actividad económica concreta de producción y consumo, de valores materiales y espirituales.

3. La Economía Sacramental de la Salud se orienta a su Valor Supremo: 'la Salud', llamada también: Plenitud de Gracia, la Gloria, la Vida Eterna, la plenitud de vida divina infundida, Visio beatifica, Beatitudo, Visión beatífica, Dios, etc.
4. La Salud: como punto final del proceso personal del cristiano y como punto final del proceso colectivo en Jesucristo, proyectado escatológicamente en el Retorno de Cristo, el juicio final y 'la Nueva Creación Espiritual' (o: 'el Nuevo Jerusalén que baja del Cielo').

5. La Economía de Crianza de la Vida se orienta a su valor máximo: 'la Vida' (pero: vida de la Pachamama como megaorganismo, que emerge y aparece en cada ser viviente: sea de la 'comunidad' de los wak'as, sea de la sallq'a o mundo silvestre, sea de la comunidad humana, los runa).

\section{Introducción: Meta-economía}

Anteriormente hemos explicado ${ }^{2}$ que el objetivo de la actividad económica del andino es la crianza de la vida como 'producción de supremo valor', un valor bidimensional que es material y espiritual a la vez. Su sistema tecnológico también es empírico-simbólico, basado en una tecnología empírica sui generis y en continuos rituales de producción para la Pachamama. Señalamos que el concepto andino de economía es un concepto bidimensional, y en lo que sigue lo analizamos en continua comparación con el concepto occidental.

Explicaremos que en la cosmovisión y la teología cristiana medieval nació el pensamiento europeo de la economía

1 Sociólogo del Desarrollo por Institut des Hautes Etudes de l'Amérique latine (IHEAL) - París. Doctor en Sociología por la Universidad Católica de Holanda (1980). Docente en Sociología del Desarrollo y Antropología Andina en la Universidad de Antofagasta e Iquique - Chile. Docente en la Universidad Libre de Amsterdam - Holanda.

2 En: Van Kessel, Juan y Cutipa, Juan de Dios (1994). Criar la Vida: Agronomía andina. Santiago: Vivarium. 
como sistema de generación y distribución de Vida Divina: la 'Economía Sacramental de la Salud'. Lo analizamos con Schillebeeckx y lo comparamos con el concepto andino de la economía como 'Crianza de la Vida'.

Finalmente se nos explica que en la economía política colonial del Cuzco sobrevivió el pensamiento cristiano medieval (Burns) y que en el pensamiento económico del runa quedó viva la conciencia Pachacéntrica de su identidad (su 'conciencia natural', Estermann). El enfoque de nuestro tema pide una reflexión previa sobre la meta-economía y los presupuestos metafísicos (mitológicos, teológicos) del cambiante concepto de 'economía'.

Es necesario introducir desde un principio y tomar en cuenta este término ("meta-economía"), para entender el concepto tradicional andino de economía: ya que para el andino, la economía no es una actividad autónoma, separada e independiente de otras actividades, noeconómicas, como el juego, la religión, la fiesta, el deporte o la política. Economía y tecnología productiva son para el andino: la Crianza de la Vida y el Saber criarla. Por eso abarca la vida en todas sus formas, dimensiones y aspectos: la vida del runa, de la sallq'a y de los wak'as.

Lo que llamamos "economía" tiene, en el mundo andino, sus raíces, su razón y su sentido final (digamos: 'su filosofía') fuera del área específica de la economía y fuera de las leyes supuestamente 'autónomas' del mercado, de la oferta y demanda, de los recursos y la productividad. Su razón está en los valores y normas de un nivel más allá de la economía: el nivel de la meta-economía y la mitología. La idea de una economía autónoma sería imposible, insana y fuera de lugar, sería 'ex-céntrica', según J. Estermann. Agrega que 'el individuo concebido como ser particular y autónomo es para el pensamiento andino algo sin lugar (u-tópico), sin fundamento (an-árquico) y sin centro ni corazón (ex-céntrico)'. En su ensayo titulado: "Elementos para la reivindicación del pensamiento colonizado" este autor señala unos principios del pensamiento andino originario que dan soporte a la tesis de la conciencia metaeconómica del andino cuando considera su actividad económica como crianza de la vida. Son los principios de (1) la relacionalidad de todo ser y todo acontecer; (2) la Pacha —el universo, el cosmoscomo sistema ético; y (3) la conciencia natural del hombre andino ${ }^{3}$.

En el concepto del andino, la 'economía', lejos de ser un saber autónomo y encerrado en sí mismo, está insertada en su cosmovisión (más bien: en su Pachavivencia). La Pacha es el mega-organismo global, vivo, del que todo ser natural forma parte y el runa también. La actividad económica es considerada 'Crianza de la Vida' de aquel mega-organismo y de todas sus partes, y estas abarcan su familia y su casa, su chacra y su entorno total.

De ahí que su economía está normada por principios éticos como (1) la complementariedad, (2) la reciprocidad, (3) la concepción cíclica del tiempo y (4) la correspondencia y transición entre micro- y macrocosmos. Entre tanto, la economía moderna, liberal, se ha 'liberado' de la tutela metafísica, de la religión y la ética, y se mueve en forma independiente al compás de la demanda y oferta en el mercado. En el mundo occidental moderno, 'economía' es una ciencia positiva y una actividad autónoma, propia de la empresa y del homo oeconomicus. Fijémonos bien en esta

3 Para evitar un aparente — y mal ubicado - homenaje a una moda pasajera, no escribimos aquí: "del hombre andino y de la mujer andina" o: "el hombre y la mujer andino/a", sino simplemente "el hombre andino" como traducción de jaque o runa. Aquí vale una nota de la antropovisión andina. Este "hombre andino" es macho y hembra; masculino y feminino. Jaque (o en quechua: runa) significa precisamente: "hombre y mujer". Jaquesiña es: hacerse jaque; hacerse gente, devenir un ser humano completo). Trabajar, producir, es concebido en el mundo andino como "criar la vida" y se refiere al esfuerzo mancomunado de hombre y mujer y éstos actúan en tinka, un concepto exclisivamente andino que expresa una mutualidad en equilibrio tenso y fértil. 
discordancia de contenidos al hablar de "economía" o de "tecnología" cuando tratamos de la realidad andina.

Por otra parte señalamos una curiosa concordancia entre (a) el pensamiento, o paradigma, andino a propósito de la economía y (b) el paradigma europeo medieval de la escolástica, radicada en la teología de San Pablo y la filosofía aristotélico-tomística: la cristología y la escatología de San Pablo (+10 - 64 DC), el hilemorfismo de Aristóteles (384 - 322 AC) y la escolástica de Thomas de Aquino $(1224 / 5$ - 1274/5) con su concepto global

\section{"La Economía de Crianza de} la Vida se orienta a su valor máximo: 'la Vida' (pero: vida de la Pachamama como mega-organismo, que emerge y aparece en cada ser viviente: sea en wak'as, sallq'as y runas."

del saber y la sabiduría que es positivo y especulativo, material y espiritual, físico y metafísico, cuerpo y alma, como el ser humano mismo y-lo que deja marca- con su jerarquía incluyente de todos los valores, espirituales y materiales. Este pensamiento teológico-filosófico mueve la vida religiosa y ética, cultural, social y económica de Europa en la época media.

En ambos paradigmas, el andino y el occidental-medieval, la economía y los elementos económicos están ordenados en una jerarquía única, universal y trascendental de valores y normas. Los elementos materiales son controlados y normados por saberes y valores de mayor categoría; en última instancia, por el concepto religioso del mundo y su máximo valor. Para el cristiano medieval el máximo valor es: 'Dios', o 'La Vida Eterna' por alcanzar; para el andino es la Vida de la Pacha por criar en todo. En ambas culturas, un tratado sobre la economía no puede prescindir de una introducción 'meta-económica', llámese filosófica, metafísica o mitológica.

\section{La economía andina tradicional}

Toda actividad del andino, sea económica, social, religiosa o artística, sea laboral, doméstica, festiva, de crianza o de educación, en su concepto se trata siempre de 'Criar la Vida'. El valor económico central para el andino es la vida, y la vida tal como el andino la experimenta y la concibe, la vida en todas sus formas: vida humana y animal, vida vegetativa y espiritual, la actividad de los muertos y del clima, y aun la vida de los cerros, las aguas, la tierra misma, la vida del universo mismo, llamada Madre Tierra, Pachamama. La vida es una y múltiple, que aparece en sus tres dominios: la vida de los wak'as, la vida de la naturaleza silvestre (la sallq'a) y la vida de los humanos (incluso los difuntos). El ayllu andino, su territorialidad, es un universo vivo que comprende tres comunidades: wak'a, sallq'a y runa.

La meta final de la actividad económica no es incrementar o acumular capitales y poder, sino criar una sumaq kawsay (una vida dulce, armoniosa, vigorosa) y es criar, vigorizar esta vida en buena armonía. Signos del sumaq kawsay son: una creciente felicidad, bienestar, seguridad, una armonía social y cósmica cada vez más completa y duradera, siendo éste el camino para incrementarse el prestigio, la fuerza y la satisfacción de los seres y comunidades implicadas. Economía, producción, significa la regeneración del sumaq kawsay (en la chacra, y de ahí en la familia humana y en la comunidad humana). Es por eso que aparecen en el discurso tecnológico andino términos como: siembra, procreación, gestación, nacimiento, crianza, cosecha. 


\subsection{La Vida}

La vida es el valor supremo para el andino; pero todo ser natural 'vive' y tiene personalidad como los humanos: los seres de fauna y flora, y también las piedras del campo, el agua de los ríos; los cerros y los fenómenos climáticos, sol, luna y estrellas. La Pachamama es la Madre universal, la que da vida a todos estos seres y los cría. El runa en su chacra es 'el partero' de la nueva vida que allí nace; es partero y criador, a ejemplo y por encargo de la Madre Criadora universal. Y el runa también se deja criar por ellos y por Ella. El agricultor sabe que después de la cosecha la Tierra debe descansar, para que 'la Virgina' se recupere después de parir los seres que le han de alimentar: "la madre papa', la mama oca, la mama quinua, la mama sara (la madre maíz)... Sabe abonar la tierra de su chacra y sabe alimentarla con sus ofrendas: la wilancha o el simple 'pago a la Tierra'.

Igualmente hace el pastor andino con su 'chacra-con-patas', su ganado, de la que cosecha la lana, la carne, la grasa... La Vida es el valor último y máximo: Vida compartida, universal, recibida como regalo por gozar y como tarea por criar, compartir y transmitir; la Vida armoniosa que se desarrolla en el diálogo y el regalo gratuito y recíproco entre humanos y también para con los seres vivos de la chacra, de la naturaleza, y de la comunidad de las wak'as, las divinidades andinas. La Vida es Una y universal, de modo que la sabia crianza de los cultivos afecta positivamente la crianza de los hijos, yel aborto afecta a la vida de la chacra: trae la granizada que acaba con los cultivos. Esto nos suene casi como 'la comunión de los santos', recitada en el Credo, o Símbolo de los apóstoles.

El respeto por la Vida, su crianza con cariño y dedicación es, en resumen, la máxima de la ética andina. De esto se ocupa el agricultor, el pastor, el pescador andino y también la madre y dueña de casa, el curandero y el yatiri, el ritualista andino. El minero, el albañil, el comerciante de la feria, el transportista andino, todos los actores económicos del mundo andino, igual que la madre y dueña de casa demuestran, en su momento, el agradecimiento, mediante un pequeño ritual de producción, una palabra o un gesto simbólico, una detallada ceremonia andina o una fiesta que acompaña sus labores. Éstas son percibidas como "crianza de la Vida', una Vida compartida entre todos, una Vida recibida de la Madre Tierra que hace que todos los seres naturales son sus hijos y que entre ellos son hermanos.

\subsection{La crianza de la vida}

Los términos y conceptos de la economía andina tienen un alcance meta-económico y religioso porque, si bien son originarios del ambiente biológico, están cargados del significado meta-económico y religioso de la Vida que se cultiva y la sumaq kawsay que se cría. Con el respeto al valor religioso de toda vida observamos que el ciclo económico andino es el resultado de tres ciclos biológicos que integran el sistema económico andino. Estos tres ciclos son:

1. El ciclo ganadero: gestar, parir, criar y beneficiar, llamado "cosecha" (la economía pastoril).

2. El ciclo climático, vegetativo y agrícola: sembrar, brotar, crecer, florecer, echar semilla y cosechar (la economía agrícola).

3. El ciclo vital humano: nacer, criarse, casarse (jaqisiña), generar y criar hijos, madurar, morir para renacer en la descendencia (la economía doméstica).

El sistema económico andino logra integrar en un modelo único las exigencias y las necesidades, las oportunidades y las reciprocidades que ofrecen estos tres ciclos biológicos, considerados en su conjunto como una misma vida que brota de la Madre Tierra, que es compartida por todos y que se desarrolla como un mega-cuerpo 
orgánico en reciprocidad solidaria y con un mismo ritmo vital.

En resumen: El pensamiento económico andino parte de la alegoría de la vida biológica. Sus conceptos básicos se han desarrollado como parte de una cosmovisión y una pacha-vivencia basadas en el concepto de un mundo vivo y un organismo universal único, el mundo como mega-organismo o mega-cuerpo. De este modo se logró un sistema económico de producción-distribución-consumo-reproduc ción que ha sido capaz de criar, vigorizar, asegurar y reproducir 'la buena vida' — sumaq kawsay — del andino/de la andina y de su mundo.

"En el pensamiento medieval de la meta-economía, no solamente con plata y oro se adquiere bienes espirituales a la Iglesia, o con ofrendas preciosas a los Santos. También se pagaba por bienes y servicios materiales con recursos."

\section{La economía cristiana medieval}

En lo que sigue comparamos este concepto andino de la comunión universal de Vida de la Pacha con un concepto bíblico de la comunión universal de Vida Divina, definido en el dogma de la 'Comunión de los Santos', que fluye por todo el 'Cuerpo Místico' del que Cristo es la Cabeza y los cristianos son los miembros vivos. Esta Vida Divina se genera y se distribuye -en términos de la teología medieval y moderna - en la 'Economía Sacramental de la Salud' (ESS) en el contexto de la 'Historia universal de la salud'. El cristiano que en su bautismo recibió de Jesucristo esta Vida divina, ha de criarla también, y en esto consiste su vida de cristiano.

Para tal efecto exponemos el concepto teológico medieval de la ESS, según Santo Tomás de Aquino y según su alumno, el doménico Eduardo Schillebeeckx: un concepto igualmente bidimensional en que la distribución de la Vida Divina representa el valor supremo por adquirir. Si sabemos que con la secularización de la cultura occidental el concepto moderno de la economía — sea capitalista, sea marxista - es un concepto científico, uni-dimensional y liberado de "la tutela metafísica', veremos también cómo se produjo el divorcio entre las dimensiones material y espiritual en el concepto antiguo de la economía y cuál ha sido su efecto para la interpretación de Tomás de Aquino que ofrece Schillebeeckx.

\subsection{La economía benedictina del ora et labora}

La mística propia de la orden de los benedictinos, fundada en el año 529, dio comienzo a una nueva economía bidimensional, concebida desde la cosmovisión religiosa de Europa medieval. Ora et labora: en este lema resumía San Benito, fundador de esta primera orden religiosa de la Iglesia Católica Romana — la única en los siguientes 500 años-la regla para sus monasterios. Las centenas de conventos de benedictinos, bajo los estímulos de Carlomagno (742(?) - 814) y sus sucesores repartidos a través de toda Europa durante los siglos IX al XII, fueron al mismo tiempo las haciendas modelos que crearon y divulgaron la cultura agrícola europea medieval.

El lema ora et labora resume el concepto de la economía y la tecnología de la cristiandad medieval y da prueba de una tecnología bidimensional (empírica y simbólica) y una economía bidimensional: 
positiva (de la producción y consumo de bienes y servicios), a la vez que espiritual (de la salud teológica). El "ora..." se refiere a la oración litúrgica de los monjes con que estaban ocupados durante cuatro horas diarias, o más, y a sus celebraciones litúrgicas atendidas por los decenas de miles de inquilinos laicos; el "...labora" abarca, aparte de las labores agropecuarias, también el trabajo intelectual y todas las industrias caseras de los monjes y de sus inquilinos, la población campesina en general. La diferencia entre el "ora..." y el ritual andino de producción, está en que la oración litúrgica - alabanza a Dios que transformaba también las labores en 'alabanza' - elevaba la tecnología y la economía hacia alturas espirituales; en cambio, el ritual andino es un ritual sacrificial de reciprocidad y canje que movilizaba las fuerzas espirituales a favor de la Crianza de la Vida, Vida de la Pacha y la Chacra, la casa y la familia.

En las ciudades medievales de Europa encontramos los gremios artesanales de carpinteros, albañiles, tejedores y muchos otros más, que eran organizaciones religiosas, a la vez que laborales. La protección celestial asegurada por el culto religioso de su Santo garantizaba la seguridad y el buen éxito de sus esfuerzos labores. Estimulados por las fiestas patronales San José apoyaba y guiaba a los carpinteros, San Eloy inspiraba y protegía a los plateros ${ }^{4} x i c o$ el particularismo en el patrocinio profesional es visible en William Spratling, celebrado como Santo Patrono de los plateros de Taxco. Ver: $<$ http://www.conaculta.gob.mx/saladepre $\mathrm{nsa} / 2004 / 18 \mathrm{ago} /$ plateria.htm $>$ particularismo en el patrocinio celestial del trabajo originario de en España, donde se cobijaban los grupos laborales y sociales en las cofradías, como se observa en las cofradías sevillanas en el siglo XVI, prototipo de las cofradías coloniales americanos. Todas las clases sociales, en sus diversos oficios, integraban las hermandades de penitencia: los Veinticuatro y Jurados celebrtaban el Cristo de San Agustín o del Santo Crucifijo; los magistrados y letrados en nuestro Padre Jesús de la Pasión; los nobles en Nuestra Señora de la Concepción, la de Regina y la de la Antigüa; los comerciantes en la Veracruz; los negros en el Cristo de la Fundación; los estudiantes en las Negaciones y Lágrimas de San Pedro; los mulatos con el Ecce Homo de San Ildefonso; los medidores de la Alhóndiga en la Entrada en Jerusalén; con el Cristo de la Expiración iban los plateros; los toneleros, en Ntra. Señora de la Luz; los alfareros y marineros acompañaban a la Virgen de la Estrella; los panaderos se agrupaban en torno al Prendimiento, etc... Ver:>. Las preciosas ofrendas de oro, plata y vestuario para el Santo, flores y cera, música, baile y comida, eran el pago indispensable para asegurarse de la protección y colaboración del Patrono celestial. Aparte de los gremios artesanales, los agricultores festejaban a San Isidro, los ganaderos a San Marco, los cazadores a San Egberto, los melificadores a San Ambrosio, los transportistas a San Cristobal. Hasta los enfermeros y los militares de las cruzadas formaban órdenes religiosos como los Templarios ${ }^{5}$, y la orden militar de Malta $^{6}$ como variantes y extensiones del ora et labora de los Benedictinos. El culto a los santos patrones expresaba un concepto espiritualista de la economía: la misma actividad laboral, la obra del Santo en vida, era continuada por sus agremiados, así lo creían los cristianos

4 En méjico, el Santo Patrono de los joyeros y plateros es San Felipe de Jesús; ver: <http://www.oremosjuntos.com/ SantoralLatino/SanFelipeJesus.html $>$

5 La Orden del Temple fue una orden medieval de carácter religioso y militar nacida de la primera cruzada y fundada en Jerusalén en 1118. En sus inicios su denominación oficial fue Orden de los Pobres Caballeros de Cristo (Pauperes Conmilitones Christi); más tarde fueron conocidos comúnmente como Caballeros templarios o Caballeros del Templo de Salomón (Milites Templi Salomonis), denominación surgida tras instalarse en el antiguo templo de Salomón.

6 La Orden de los Caballeros del Hospital de San Juan de Jerusalén, desde 1530 llamada "La Orden de Malta", pero fundada en Palestina en el siglo XI, fue primero una orden hospitalaria para la atención de los hospitales de peregrinos a Jerusalén), pero tomó pronto carácter militar en su lucha contra los musulmanes, en el marco de las Cruzadas. 
El culto religioso patronal era fundamental para la actividad laboral, para el sistema productivo y para la economía medieval en general; y hasta hoy día, las fiestas patronales no han desaparecido del mundo andino ${ }^{7}$. La promesa, o "manda" como práctica religiosa popular en los países andinos es otra expresión del concepto de una economía bidimensional que perdura desde el catolicismo primordial de la colonial predicado por los misioneros españoles y que indudablemente fue acogido e

"El paradigma medieval se encuentra cristalizado en la Summa Theologica, obra magna de Tomás de Aquino."

interpretado por los indígenas conforme su propia ritualidad agraria y su tecnología agraria simbólica y bi-dimensional. Como un aspecto más en el proceso de mestizaje y "cholificación"; el término es de Bourricaud $^{8}$,

En el pensamiento medieval de la metaeconomía, no solamente con plata y oro se adquiere bienes espirituales a la Iglesia, o con ofrendas preciosas a los Santos. También se pagaba por bienes y servicios materiales con recursos espirituales. La historia de las cruzadas lo ilustra con abundancia.

1. En $1096{ }^{9} \mathrm{el}$ Papa Urbano II fue el primero en financiar los altísimos costos de la primera Cruzada y remuneraba los esfuerzos de sus combatientes-peregrinos con indulgencias ${ }^{10}$.

2. En $1207^{11} \mathrm{el}$ Papa Inocencio III solicitó al Rey Felipe Augusto de Francia que mandara un ejército exterminador al Sur de Francia para acabar con los Catharistas porque no se habían convertido con la prédica de los domínicos. Y le ofreció indulgencias muy similares a los concedidos a los caballeros de las cruzadas.

3. En 1506, el Papa Julio II inició la construcción de la basílica de San pedro y del palacio del Vaticano y para financiar los altísimos costos publicó una indulgencia a quien colaborara con su limosna en la construcción de las obras. El Papa León X renovó dicha indulgencia en 1514.

Notemos bien que los abusos ${ }^{12} \mathrm{y}$ tráfico de indulgencias fueron uno de los motivos por los cuales Lutero se enfrentó con la

7 Este concepto sobrevive no solamente en la religiosidad popular andina sino también en la teología de fondo que respalda la doctrina social de la Iglesia Católica: esta dice que el significado del trabajo, sl valor espiritual y la vocación del trabajador están en el trabajo humano completa la obra divina de la creación del mundo.

8 Bourricaud, François. ¿Cholificación? en: Matos Mar, José. El indio y el poder en el Perú. LIMA: Moncloa-Campodonico; 1970, pp. 183-198.

9 Armstrong, 2001, c.4.

10 En la doctrina católica, la indulgencia da la remisión de la pena temporal correspondiente a pecados ya perdonados, con que se exime de penas de carácter espiritual que de otro modo los fieles purgarían luego de la muerte en el purgatorio.

11 Armstrong, 2001, c.9.

12 Lo que suscitó el malestar en Alemania fue el permiso otorgado a Alberto de Brandeburgo para predicar la misma indulgencia, solamente que con otros fines. El arzobispo había contraído una copiosa deuda con los conocidos banqueros Függer que le habían adelantado dinero para poder hacerse de una tercera diócesis, Maguncia. El dispositivo ideado para saldar la deuda fue que la mitad de las limosnas recogidas en la predicación de la indulgencia irían a parar a manos de los banqueros, y la otra mitad iría a las arcas de la Cámara Apostólica. Este hecho, sumado a una teología torcida sobre los efectos de la indulgencia en los muertos (se decía en la predicación popular "No bien cae la limosna en el cestillo el alma sale del purgatorio"), inflamó a toda Alemania. 
Iglesia Católica. Por la oposición misma visualizamos los primeros vestigios de una idea nueva y moderna de la economía, ya no bidimensional, sino exclusivamente material y terrenal, y en todo separado de la ESS. Ésta respondía al principio del sola fides con que el cristiano adquiría los beneficios de la salvación merecido por el sacrificio de Jesucristo en la Cruz.

\subsection{Tomás de Aquino}

Según Santo Tomás de Aquino, citado en Eduardo Schillebeeckx, "la verdadera economía (universal y trascendental) es la Economía Sacramental de la Salud". Evocamos aquí el pensamiento cristiano medieval en su fase madura y clásica, porque en él encontramos con más nitidez el parangón del pensamiento mitológico andino centrado en la Pacha como el megaorganismo vivo que incluye en un solo ayllu universal a las tres comunidades y todos sus componentes vivos: runa, wak'a y sallq'a. El paradigma medieval se encuentra cristalizado en la Summa Theologica, obra magna de Tomás de Aquino.

En esta obra, el filósofo recapitula y ordena todos los sistemas particulares del pensar medieval: teología, filosofía, ciencias positivas, en un mega-sistema inclusivo, coherente y perfectamente jerarquizado, que es la expresión de la perfecta orientación del universo espiritual, humano, animal, vegetativo y mineral -universo llamado "la Creación"- y esta orientación es hacia su Creador. Esto no es un mero ejercicio académico, sino el modelo ético-religioso de la vida del cristiano de la época. En esta cosmovisión el cristiano encuentra la perfecta integración jerarquizada de todos los valores: religiosos, éticos, psicológicos, sociales, económicos, estéticos, artísticos, tecnológicos... Todos ordenados hacia el Valor Supremo por alcanzar, que es Dios.

Aquí, el Valor Supremo es un valor escatológico por alcanzar in extremis a través de toda una vida cristiana sacramental. El Valor Supremo tiene varios nombres: 'la Vida
Eterna', 'el Descanso Eterno', 'el Descanso en Dios', 'la Salvación (del alma)', 'la Gloria', 'la Salud', etc., y en los términos doctos de Aquino: Visio beatifica, la eterna visión mística, contemplativa de Dios. La Vida Eterna - premio para toda una vida cristiana sacramental correcta - tiene en la cosmovisión andina su parangón en la Vida de la Pacha de siempre, Vida por criar, vigorizar y hacer brillar, no en el más allá, sino en la Pacha de siempre: el ayllu. Tomás de Aquino desarrolla su 'Economía Sacramental de la Salud' (ESS) cuando trata de la 'Historia de la Salud', centrada en la Pascua del Señor, esto es: su pasión, muerte y resurrección. Esta Historia de la Salud fue iniciada en la Creación del mundo (Gn 1-3) y culminará en la Nueva Creación representada en el Jerusalén Celestial que ha de aparecer con la segunda venida de Jesucristo (cf. Ap).

Otro detalle de los paradigmas por comparar es la visión del tiempo. Donde la percepción del tiempo-Pacha es multi-cíclica y coincidente con el ciclo meteorológico anual, encontramos en la visión cristiana del tiempo un solo mega-ciclo que va desde la Creación y el Paraíso Terrenal hasta el Fin del Mundo y el Paraíso Celestial, pasando por la figura de Jesucristo, que baja del Cielo y luego asciende a Dios (esto es: 'la Encarnación (o Humanización) del Verbo' y la 'Divinización del Hombre' tocado por Jesucristo y su sacramento). Esta visión del tiempo como mega-ciclo único produjo en Occidente una percepción histórica y lineal del tiempo junto a la ética comprometedora de la Historia de la Salud, universal y personal; y en tiempos modernos con una ética similar, ahora secularizada pero no menos desafiante, del 'Progreso' (y no se pregunta: ¿Progreso, a dónde?).

\subsection{Schillebeeckx y la economía sacramental de la salud}

Eduardo Schillebeeckx, principal teólogo del Concilio Vaticano II (1960-1963), analizó y sistematizó en forma magistral la teología fundamental de Santo Tomás de Aquino, 
resumida en la 'Historia de la Salud' y la 'Economía de la Salud'13. En sus momentos extremos esta 'Historia' se expone en términos mitológicos. La creación del hombre y su caída en el pecado constituyen el inicio y caracterizan la condición humana como un estado de desgracia y culpa, condena y muerte (ver: Gn 1 -3). Su final mitológica se proyecta en la vuelta de Jesucristo en Gloria y Poder para proclamar el juicio final de la humanidad que ha de separar a los cristianos fieles de los infieles. Los primeros son hijos de Dios que en su bautismo recibieron el germen de la Vida Divina, Eterna. Los infieles siempre son presos de Satanás y

\section{"Señalamos una marcada} similitud entre el concepto de la 'Comunión de los Santos' y el concepto andino del megaorganismo vivo - la Pachaen el que participan todos los seres vivos de runa, sallq'a y wak's."

destinados a la Muerte Eterna (el infierno). A los primeros, Jesucristo ha de introducirlos en la Gloria (ver Ap 21 - 22).

El centro y la bisagra de la Historia de la Salud la forma el Jesús histórico, reconocido hijo de Dios, con su misión centrada en su pasión, muerte y resurrección. El significado es: 'El Verbo (Dios) se hizo Carne (humano)' para recapitular la humanidad condenada y divinizarla nuevamente como en su estado de gracia original en el paraíso. Por la fe en
Jesús y la marca de los sacramentos, el hombre 'se salva', es decir: el contacto vivificante con Jesús (sea Jesucristo histórico, sea el Cristo místico, resucitado) incluye a los humanos en este devenir de la 'Nueva Creación', el llamado 'Jerusalén Celestial', que es la expresión de la Salud, o la 'Vida Eterna'. La historia universal de la Salud se realiza y se repite en cada ser humano, llamado a la fe y los sacramentos, por cuanto éstos incorporan a los humanos como miembros vivos del Cuerpo Místico de Jesucristo y les transmiten la Vida Divina de 'la Cabeza' del 'Cuerpo' (Jesucristo), Vida que se desarrolla y se fortifica por una vida llevada según las enseñanzas de Jesús y alimentada continuamente por sus sacramentos. Ésta es en breves palabras la 'Historia de la Salud'.

\subsubsection{La comunión de los santos}

Aunque muchos fieles lo ignoran, el dogma cristiano de 'la Comunión de los Santos' significa la circulación de la Vida Divina entre la Cabeza del Cuerpo Místico (Jesucristo) y sus miembros (los santos y los cristianos). De este modo cada cristiano participa en el mérito de Jesucristo y de los demás santos y cristianos. Podemos interpretar la circulación del mérito y de la Vida Divina (realizada en la Eucaristía y la comunión sacramental) en los términos de la Economía Sacramental de la Salud, como: 'distribución de la Vida Divina, Valor Supremo generado mediante el sacrificio de Jesucristo en el Calvario'. En efecto, de la doctrina del 'Cuerpo Místico de Cristo' y de la 'Comunión de los Santos', la Economía Sacramental de la Salud es una economía altamente solidaria y comunitaria. La Vida de gracia es una sola y es totalmente compartida entre todos los miembros del Cuerpo unidos a la Cabeza, Jesucristo.

Señalamos una marcada similitud entre el concepto de la 'Comunión de los Santos' y el concepto andino del mega-organismo

13 Schillebeeckx, Edward (1952) Christus en Zijn sacramentele heilseconomie [Cristo y su economía sacramental de salud]. Antwerpen. En: Obras. 2. Idem Christus en Zijn sacramentele genadebemiddeling [Cristo y su medianía sacramental de la gracia]. En: Obras. 2. 
vivo - la Pacha - en el que participan todos los seres vivos de runa, sallq'a y wak's.

\subsubsection{La historia de la salud}

A continuación, tanto Tomás de Aquino como su intérprete Schillebeeckx, exponen que la Historia de la Salud se realiza en la 'Economía Sacramental de la Salud', tanto a nivel de la historia humana universal como a nivel de la historia personal del cristiano. Esta historia es, en breves palabras, el proceso de la generación y distribución de los 'Frutos de la Salvación' adquiridos por Jesucristo mediante su muerte en cruz. Estos 'frutos' son 'La Vida Eterna' mostrada anticipadamente en la Resurrección de Jesucristo del sepulcro, pero también en la Vida celestial que gozan María ('la Virgen Asunta'), los santos y las almas benditas y que es la misma Vida Divina de Jesucristo.

Es muy característico que Schillebeeckx en su 'La Economía Sacramental de la Salud' ya no trata de una economía bidimensional (que sería: material-espiritual), tal como lo hizo su maestro, Tomás de Aquino, sino que se limita a desarrollar la dimensión espiritual, aunque sin rechazar que la economía moderna está relacionada con la Historia de la Salud y con la 'Economía Sacramental de la Salud'. El amor místico hacia Jesucristo se muestra en una 'vida según las enseñanzas de Jesucristo' y sólo este amor hace operativos a los sacramentos vitales. La sugerencia es que en el tratado de la Teología Moral este amor místico sería tratado y desglosado en términos del fiel cumplimiento de la Ley de Dios en el diario vivir, personal y social, lo que incluye la actividad económica del cristiano. Ya no vemos cómo la actividad del homo economicus y de la empresa económica se integran en la Economía de la Salud.

Schillebeecks define la Historia de la Salud - llamada también "la Obra de la Salvación de Jesucristo", centro y bisagra de esta 'Historia' - como un proceso histórico universal que se repite a nivel individual por el Espíritu Santo (de Pentecostés) en que se activa el Pneuma (la operación del Espíritu Santo) de los sacramentos. "La Salud se logra por una vida de libre empeño del hombre, llevada por una gracia cristiana específica, como participación a la plenitud de gracia de Jesucristo mismo, con quien entramos en contacto mediante la 'Economía Sacramental de la Salud"' (Schillebeccks 1952: 5). Tal conducta humana se regula por una moral que es cristológica y teocéntrica (Idem: 4). Por la conducta cristiana apoyada en los sacramentos se tiene acceso al valor supremo de la 'verdadera economía', la Salud. Ésta comienza aquí en la tierra, en bautismo y vida de gracia cristiana, y se manifiesta en plenitud cuando cae la 'envoltura del cuerpo; cuando el mundo desaparece y el Reino de Dios aparece en plenitud' (Ap 20-21).

En términos teológicos se concibe la Historia de la Salud como el ciclo de Dios en Cristo ('el ciclo de Salida-Retorno (ExitusReditus)') estructurado en estas fases: Creación (Exitus), Asunción original en Gracia (de Adán), Caída en pecado, Redención por Jesucristo y su Medianía sacramental de la Gracia (el Reditus; Idem: 3s.). La Medianía sacramental de la Gracia, se expone sucesivamente en los tratados de la Cristología (que es base de) la Eclesiología (siendo la Iglesia considerada como 'Cuerpo Místico de Cristo' y 'proto-sacramento') y finalmente los sacramentos, que son las siete fuentes de Salud que emanan del protosacramento. Los sacramentos son: viae ad beatitudinem ('caminos a la felicidad'), son los órganos últimos de la Salud por los que el hombre alcanza su destino y así se realiza formalmente el Reditus (Idem: 6). De ahí la definición de la Economía Sacramental de la Salud como 'el retorno de las criaturas racionales hacia Dios': reditus rationalium creaturarum in Deum (Idem: 6).

\subsubsection{La Economía Sacramental de la Salud}

Finalmente encontramos la definición de la Economía Sacramental de la Salud en términos teológicos precisos: dispensatio 
divinae salutis ex merito divini Salvatoris, victima pro mundi salute: "La distribución de la Salud divina originada en el mérito del divino Salvador (Jesucristo), víctima para la Salud del Mundo". Podemos resumir la perspectiva teológica de la Economía Sacramental de la Salud, según Schillebeeckx y su interpretación de Tomás de Aquino en estos términos: La Economía Sacramental de la Salud se encuentra en la perspectiva magna del Reditus de toda la creación hacia Dios. Pero Cristo, Cabeza de la Iglesia, es el proto-sacramento, tal como lo enseña también la literatura patrística, por lo que el

\section{"La deuda de Adán y del}

hombre pecador está sujeta a

una economía de satisfacción

de la culpa. El mito del

pecado de Adán enseña que

la deuda contraída por Adán

se paga con el trabajo sufrido, los dolores de parto y la muerte."

Reditus del hombre y de toda la creación se hace posible. (Idem: 16s.).

Recapitulamos lo anterior: La actividad salutífera de Jesucristo considera: la producción efectiva de la Salud centrada en la Pascua del Señor y su distribución entre los humanos, centrada en la actividad salutífera de la comunidad eclesial viva, que es Cuerpo Místico de Jesucristo y proto-sacramento de Salud. En la comunidad eclesial -'la Iglesia'se realiza para los cristianos la actividad salvífica de Jesucristo, encarnado, glorificado y sacrificado, muerto y resucitado. La actividad 'económica' de los cristianos para adquirir la Salud es de 'receptividad activa' en la celebración de los sacramentos.

Pero ¿cuál es la continuidad entre las dos 'economías': la espiritual y la material? Y ¿cuál es la oposición y el enlace entre ambas? La Salud (la Gracia divina, la Vida divina, los bienes celestiales, bienes eternos) se contrapone a los bienes terrenales, como el Espíritu a la Carne. La vida eterna del cristiano está radicada en su vida mortal y en el buen uso de los bienes materiales, perecederos; la economía de la salud radica en la economía de los bienes materiales. La pregunta se hace: si se trata de una sola economía (bidimensional) o de dos economías (unidimensionales); de una sola economía bipolar y jerarquizada, o de dos economías autónomas y en constante oposición. Tomás de Aquino percibe indudablemente una sola economía marcada con la misma unidad 'hile-morfística' que la unidad de cuerpo y alma de la persona humana y que es 'de cuerpo y alma'. Schillebeeckx -sin negar a su maestroconsidera en sus libros solamente la Economía Sacramental (Espiritual) de la Salud, y deja la otra a la consideración de los economistas, pecando así 'por silencio' ante el fenómeno moderno de una economía de mercado: que es materialista, autónoma y unidimensional.

\subsection{La liturgia católica}

¿Continuidad entre las dos dimensiones de la economía u oposición entre las dos partes de una economía 'partida'? Los textos litúrgicos de la Iglesia católica son ambiguos en este aspecto, y sus oraciones oficiales sugieren alternativamente ambas visiones. En sus fórmulas, los 'bienes materiales' y 'los bienes celestiales' representan dos economías, ora opuestas y/o incompatibles, ora jerarquizadas:

- 1. Oposición entre los 'bienes materiales - bienes celestiales': "Oremos: Señor Dios Nuestro y Padre Celestial: da nos usar los bienes terrenales de tal manera que no perdamos los bienes celestiales, por Jesucristo, tu Hijo y nuestro Señor, que 
contigo vive y reina en unión con el Espíritu Santo y es Dios, por los siglos de los siglos.- Amén."

- 2. Continuidad, enlace y jerarquía entre las dos economías y entre los respectivos 'bienes materiales y bienes celestiales': "Oremos: Señor Dios Nuestro y Padre Celestial: da nos usar los bienes terrenales de tal manera que adquiramos los bienes celestiales, por Jesucristo, tu Hijo y nuestro Señor, que contigo vive y reina en unión con el Espíritu Santo y es Dios, por los siglos de los siglos.- Amén."

\subsection{La deuda}

En la economía moderna y capitalista aparece, aparte de los conceptos de escasez y carencia de bienes necesarios, también el concepto de la deuda, esto es: una obligación económica combinada con la carencia de recursos. Las deudas conducen al fracaso de la empresa y a la bancarrota: el endeudado desaparece simplemente del proscenio económico (el mercado). En la Economía Sacramental de la Salud se trata de una deuda moral ante Dios, acarreada por el pecado. El término más común es 'culpa', que indica que el humano es responsable por la carencia del mérito divino derivado de la Pascua de Cristo. En la Economía Sacramental de la Salud la culpa tiene por perspectiva: la condena divina y la Muerte Eterna, es decir: 'el Infierno'.

En la economía andina de crianza encontramos la situación de estar fallando en la obligación de practicar reciprocidad con ofrendas y regalos. Ina Rösing lo llama Opferschuld ['endeudamiento ritual'], término que indica este desequilibrio en que el runa ha incurrido ante sus wak'as perjudicando la Vida en cualquier forma.

Siempre se deben ofrendas o 'pagos' a las divinidades, las almas, los humanos (aynis). La flojera y mal trabajo (no conforme a la tradición) son relaciones desequilibradas y no atendidas, que falta arreglar para que la Vida florezca y brille plenamente. Este endeudamiento afecta a la vida misma: la deteriora (daño en la chacra), por pestes, problemas climáticos, por enfermedades y pérdidas en el ganado, mala suerte, enfermedades en la familia, accidentes.

\subsection{El pago de la deuda}

La deuda de Adán y del hombre pecador está sujeta a una economía de satisfacción de la culpa. El mito del pecado de Adán enseña que la deuda contraída por Adán se paga con el trabajo sufrido, los dolores de parto y la muerte (Gn 3). El mito del pecado original enseña también la solidaridad del género humano en el pecado y en la deuda/culpa. La intervención de Jesucristo, sacrificado en reemplazo por el mundo pecador ('Cordero de Dios, que quita los pecados del mundo...') y llamado también 'el Segundo Adán' (2 Co 5: 17), enseña la solidaridad del género humano en la Economía de la Salud recuperada en Cristo.

Básicamente la deuda es pagada con el sacrificio de Jesucristo. Pero el humilde sufrimiento del pecador arrepentido (y del santo), en unión con el sacrificio de Cristo, vale como complemento expiatorio: tanto para él mismo, como para los demás miembros del Cuerpo Místico de Cristo.

\subsection{El divorcio de los dos mundos y sus economías}

El concepto del 'trabajo' ejemplifica mejor la unidad bi-dimensional de la economía en la cosmovisión escolástica. Tomás de Aquino definió principios éticos que ordenan la actividad económica y el trabajo en relación a valores no-materiales y superiores. El producto de la actividad económica, la riqueza, es 'para subsistir y compartir', para 'ayudar al necesitado', para 'hacer el bien', 'conseguir perdón de los pecados' y 'hacer obras de penitencia'. En cambio, en la teología de Juan Calvino (1509-1564) ya se ha roto esta unidad. Economía y trabajo pertenecen al 'mundo mundano' y son destinados al fuego (del "fin del mundo", y/o del infierno). No tienen nada que ver con la vida espiritual del hombre predestinado a la Vida Eterna. Ciertamente el trabajo tiene una 
norma ética, debe ser 'honesto y sacrificado', pero no ayuda para conseguir perdón, o acumular mérito ante Dios.

Este concepto de trabajo, además de la tendencia de postergar sistemáticamente el goce de los bienes generados, marca la 'ética protestante', estimula el bienestar y la acumulación de riqueza. Bienestar y riquezas no tienen ningún interés ante Dios y no son recurso para conseguir perdón de los pecados o inscripción en el 'Libro de la Vida' (la predestinación a la Vida Beatífica). Los bienes materiales y los bienes espirituales (celestiales) pertenecen a dos mundos distintos e incompatibles: lo mundano y lo espiritual (del Espíritu Santo). Sin embargo, bienestar y riquezas materiales (ganadas por trabajo honesto y sacrificado) son un signo de la benevolencia de Dios para con sus elegidos: los predestinados a la Vida. Para el protestantismo observamos la separación de la vida del cuerpo y la del alma, y la separación total de los valores correspondientes:

- 'El hombre carnal' es del mundo actual en que se manejan los bienes materiales que están todos 'destinados al fuego'; tiene una vida temporal (la muerte; el fin del mundo); el que vive 'según la Carne' está destinados al fuego del Infierno.

- 'El hombre espiritual': 'los escogidos y separados del mundo', son destinados al Jerusalén celestial, espiritual (la Vida Eterna en el más allá). La 'riqueza de este mundo', producto de la actividad económica está 'destinada al fuego'. La doctrina calvinista de los dos mundos incompatibles es derivada de la segunda carta de San Pablo a los Corintios: (2 Co 5: 1-4):

Entre tanto, la teología calvinista ayudó poderosamente a que en la cultura occidental moderna haya cambiado el significado de actividad económica y su producto, la riqueza, de un concepto bi-dimensional, ético-religioso a la vez que material y empírico, a un concepto unidimensional referido a la producción y el consumo de bienes y servicios. En su consecuencia, cambios más que revolucionarios sufrieron los conceptos de trabajo y de tecnología, que evolucionaron de contenidos de alto significado religioso y de máximo interés ético ${ }^{14}$ y pasaron a representar un simple valor material en el mercado $^{15}$. En este contexto Schillebeeckx, en la exposición de su tratado de la Economía Sacramental de la Salud, no puede sino ignorar la economía de valores materiales de mercado: porque ahora es otro tema y pertenece a otro mundo. En lo principal, su tratado de los sacramentos no puede ser sino teocéntrico y su visión de la existencia del cristiano en este mundo es la de una habitación temporal: como una 'carpa provisoria' a la espera de la 'casa definitiva'.

También para el andino, lo divino está dentro del Pacha y no lo trasciende; de modo que la vida del Pacha en que participa también el runa, es divina. Su razón de ser y toda su actividad -económica, religiosa, social, familiar...- es criar en todo la Vida de la Pacha. La actividad económica lograda, digamos: 'la feliz crianza de la Vida', implica para el andino una triple actitud: técnica, ritual y ética.

- 1. Actitud técnica: habilidad, prudencia y experiencia empírica en la 'crianza de la vida'.

- 2. Actitud ritual, porque la tecnología andina es bi-dimensional: tiene una dimensión simbólico-religiosa, expresada en los rituales de producción que acompañan la 'crianza de la vida'.

- 3. Actitud ética de cariño y respeto, responsabilidad y solidaridad: una 'ética cósmica' (Estermann) ante la 'crianza de la vida'.

El sentido de la actividad laboral del runa es la crianza de la vida. Por la feliz crianza de

14 Cf. Gn 3: 'Castigo por el pecado'; cf. San Pablo: 'Sacrificio, expiación y caridad'; cf. San Benedicito: Ora et Labora: Alabanza al Creador.

15 Cf. Adam Smith y Carlos Marx: 'un insumo para producir bienes y servicios, por comprar bajo contrato'. 
la Vida el runa gana creciente prestigio y satisfacción.

En cambio, para lograr la Salud espiritual y la Vida eterna el cristiano debe llevar una vida litúrgico-sacramental en una actitud de receptividad activa, a la vez que vivir una mística de Amor a Dios y practicar una ética de amor al prójimo. Esto incluye la constante oración junto a una disposición a renunciar a los valores materiales: 'sacrificar los bienes temporales para no perder los bienes celestiales'. Más allá del valor económico y temporal, el trabajo adquiere valor espiritual de expiación y sacrificio personal; y el producto del trabajo más allá de su valor en el mercado, puede adquirir valor espiritual de ofrenda, sea en el contexto del culto, sea en el contexto de limosna o caridad. Con todo, una actitud bastante reservada, hasta negativa, del cristiano ante los valores temporales y la vida natural, desestimados todos como 'carpa' a la espera de la casa definitiva.

\section{Burns: la economía espiritual del Cusco}

Durante la administración colonial ambos paradigmas bidimensionales - ECV y ESSse encontraron en verdadera confrontación. Doctrineros y curas, conventos e iglesias tuvieron grandes ingresos 'materiales' sin desarrollar otra actividad económica que la de prestar servicios 'espirituales'. Encontramos orgánicamente entretejidos la producción, distribución y consumo de bienes y servicios 'espirituales' o 'eternos', de la Iglesia con la producción, distribución y consumo de los bienes y servicios 'materiales' o 'temporales', tal como lo demostró Burns en el caso de los conventos cuzqueños. Por otra parte, el tejido económico colonial incorporaba tanto la República de Indios como la República de Españoles.

La economía de Cuzco estudiada por Kathryn Burns ${ }^{16}$ es un ejemplo de una economía bi-dimensional, en la que el dinero y los 'bienes materiales' tienen —además de su valor de mercado - un valor 'extra', superior a lo material, un valor espiritual, que llamamos 'meta-económico' y que solamente se puede apreciar desde la cosmovisión religiosa de la época. En su libro Colonial habits: Convents and the spiritual economy of Cuzco, Perú, Burns presenta la historia económica, social y política de los tres más antiguos conventos para monjas del Cusco: Santa Clara (fundado en 1558), Santa Catalina (desde 1605) y Santa Teresa (desde 1673) y expone su papel central en el sistema de control de los españoles sobre la elite inca y sobre el sistema económico del Cuzco colonial.

Analizando este sistema económico, la autora lo define como una 'economía espiritual', 'porque genera capital material y espiritual entretejiendo acción financiera $\mathrm{y}$ religiosa y adquiriendo bienes espirituales con dinero'. Las monjas recibían substanciosas limosnas, donaciones para mayor esplendor del culto y legados de personas ancianas y moribundas, con el compromiso de orar por el descanso de sus almas, y hacerles cantar periódicamente misas de requiem. Los conventos acumularon así considerables bienes de capital, mayormente en forma de tierras y haciendas, lo que les permitía ofrecer préstamos millonarios a autoridades, mineros y comerciantes. Los conventos eran 'las manos orantes dirigidas hacia el cielo', en cualquier desgracia pública, cataclismo o epidemia. El culto litúrgico y la oración de las monjas aseguraban el bienestar público y procuraba la bendición del cielo sobre los cultivos, la agricultura, la minería y el comercio. Burns explica cómo esta economía espiritual aseguraba el bienestar colectivo y la posición social prestigiosa de las monjas a la vez que la salud espiritual de sus benefactores. Finalmente señala aspectos de cambio y continuidad en este panorama en el momento de la formación del Estado republicano liberal. 
La autora atiende continuamente el contexto histórico de control colonial (en la intersección de género, raza y clase) sobre la elite y pueblo inca y el de la política evangelizadora y transculturizadora. La conquista de América y el gobierno colonial mismos eran considerados como una empresa misionera, una misión política y religiosa al mismo tiempo, en la línea de las Cruzadas a Tierra Santa y de la reconquista de España sobre los musulmanes, todo para defender y ampliar 'el Reino de Dios', que Jesucristo fundó con su martirio en el Calvario y luego recomendó a los apóstoles y a su vicario personal en la tierra —el Papa de

"El pensamiento andino no

es centrado en torno a una

realidad espiritual,

sobrenatural, fuera de la

Pacha, ni tampoco en torno

al sujeto humano, no es ni

teocéntrico ni

antropocéntrico."

Roma - quien, a su vez, selló el famoso pacto con la corona española: en particular con los reyes católicos, Fernando e Isabel, y sus sucesores.

En este contexto histórico se comprende que el concepto de la economía también es 'pre-moderno' y 'bidimensional', y solamente explicable desde el sistema vigente de valores metaeconómicos. Del estudio de Burns concluimos que el concepto colonial de la economía había guardado su carácter bidimensional y en buena parte también su identidad medieval. Sin embargo, a pesar de la resistencia indígena, desarrollada en la semiclandestinidad y el camuflaje de "las costumbres' (de hecho, los rituales andinos de producción), la comunidad andina tuvo que acomodar su economía y su pensamiento económico al sistema colonial dominante. ${ }^{17}$

\section{Estermann: la conciencia natural del runa}

La vivencia de la cristiandad medieval y el pensamiento de Tomás de Aquino se origina en una conciencia sobrenatural. El mundo espiritual, Dios, los sacramentos, el culto litúrgico eran la realidad verdadera y formaban el fundamento del mundo material, pasajero. La 'conciencia espiritual' es una herencia de la teología de San Agustín (354-435 d.C.) y su filosofía neoplatónica y del idealismo del mismo Platón (429-347 a.C.), para quien el mundo de las ideas representa la realidad verdadera y eterna, mientras los seres y objetos materiales, cambiantes y perecederos son sólo un mundo irreal de apariencias.

El centrado en torno a una realidad espiritual, sobrenatural, fuera de la Pacha, ni tampoco en torno al sujeto humano, no es ni teocéntrico ni antropocéntrico.

Según José Estermann ${ }^{18}$, la 'conciencia natural' del ser humano andino recalca la afinidad y complementariedad fundamental entre naturaleza humana y la naturaleza non-humana, entre el runa por una parte y por otra su chacra y su ganado, su entorno natural de la sallq'a y su entorno espiritual de las wak'as. No existe más que la 'Pacha', el

17 Sería difícil decir, en este momento, cómo, y hasta qué punto, las dos 'filosofías económicas' se han influenciado durante el proceso progresivo de la 'integración' de los dos sistemas económicos. El análisis de los testamentos de los kurakas y el estudio etnohistórico correspondiente nos enseñaría el camino.

18 Cf. Estermann, José (1997) "Elementos para la reivindicación del pensamiento colonizado". En: Cuadernos IECTA N 12 :

"Filosofía Andina". Iquique: IECTA. 12. También en: Idem (2006). Filosofía Andina: Sabiduría indígena para un mundo nuevo. La Paz: ISEAT. $187 \mathrm{ss}$. 
universo temporal-espacial, concebido como ayllu universal con sus tres comunidades 'naturales' de los runa, la sallq'a y los wak'as. En el Ayllu-Pacha, la posición privilegiada del ser humano no se debe a su desnaturalización (su conciencia sobrenatural), sino a su lugar dentro del sistema cósmico, que se determina relacionalmente. En éste el hombre tiene una posición intermedia (y mediadora), como una chakana entre los acontecimientos cósmicos y el proceso natural en el ámbito terrestre. Si el hombre se desliga de las relaciones diversas del mundo natural, esto significa entonces su caída, como individuo o como especie. Sobreponerse a la 'conciencia natural' (como ocurre, entre otros, en el tecnicismo, pero también en el misticismo cristiano) es finalmente una orgullosa impertinencia que amenaza la vida, que atomiza y 'absolutiza' (es decir: 'suelta de las relaciones') al ser humano.

Efecto de la conciencia natural del andino es que el runa no se considera en primer lugar productor, o hacedor, a imagen y semejanza del Supremo Hacedor, sino que es cultivador (es decir: 'cuidante'); la fuerza propiamente productora es la Pachamama que genera vida en un intercambio con los fenómenos celestes (sol, luna, 1luvia). Ella es la madre de todo: animales y vegetales, cerros y paisajes, fenómenos naturales y ecológicos e incluso del runa: una cosmovisión pacha-céntrica, parangón de la cosmovisión teocéntrica de la cristiandad medieval y la cosmovisión antropocéntrica del mundo occidental moderno. Por lo tanto el ser humano es en primer lugar y sobre todo agri-cultor y en toda su actividad humana criador de vida.

Una relación parecida de cuidado y profundo respeto se muestra también hacia los animales; muchos animales son para el hombre andino compañeros de camino y de infortunio que merecen protección y respeto.

La doctrina cristiana dice que este mundo es pasajero, dedicado al fuego, y que el mundo venidero es un mundo espiritual y eterno; su mensaje es: Viene el reino espiritual de Dios, el nuevo Jerusalén espiritual; su principio ético es: sacrificar los bienes materiales y no disfrutar de ellos para asegurarse de los bienes espirituales.

El dualismo cristiano entre lo espiritual y lo material, el dualismo occidental entre lo animado y lo inanimado, entre lo vivo y lo inorgánico no tiene importancia para el hombre andino. La Pachamama es una persona que tiene sed y que siente dolor cuando es arañada (es decir: arada); llamas y alpacas, pero también manantiales y cerros tienen alma y entran en contacto con el hombre.

La 'conciencia natural' es expresión y consecuencia del hecho fundamental de la relacionalidad de todo ser, lo que debe ser entendido e interpretado como primero y más importante principio de la filosofia andina. Romper, o sacrificar, las relaciones co-existenciales intra-mundanas es absurdo y fatal. Los dogmas del Cuerpo Místico de Cristo y de la Comunión de los Santos sancionan la conciencia sobre-natural del cristiano y le obligan al desapego de los bienes materiales, temporales, y sacrificarlos para asegurarse el acceso a la Vida (espiritual, eterna, la Salud).

\section{Conclusión: 'cuidar el jardín'}

El esquema 1 resume los términos y conceptos centrales manejados más arriba:

Esquema 1

\begin{tabular}{llll}
\hline MEDIO CULTURAL ECONOMÍA CORRESPONDIENTE VALOR ECONÓMICO SUPREMO & FUNDAMENTO META-ECONÓMICO \\
\hline Cristiano medieval: & Economía Sacramental de la Salud & Vida divina; beatitudo & Cosmovisión teocéntrica \\
\hline Occidente moderno: & Economía de Mercado & Bienestar (material) & Cosmovisión antropocéntrica \\
\hline Ayllu tradicional: & Economía de Crianza de la Vida & Sumaq kawsay, vida dulce & Cosmovisión Pacha-céntrica \\
\hline
\end{tabular}


En el pensamiento de Tomás de Aquino, la solidaridad existencial de los cristianos en pecado y culpa, y en Salud y Vida se prolonga en un sistema económico solidario de los bienes materiales con práctica de caridad general y de mensa communis (mesa común) en los conventos. Schillebeeckx en cambio vive en un mundo moderno de libre mercado y una economía altamente competitiva y liberada de toda tuición religiosa y ética cristiana; limita su discurso a la economía sacramental de los bienes espirituales. El alumno abandonó la idea de la economía

"El pensamiento andino no

es centrado en torno a una realidad espiritual, sobrenatural, fuera de la Pacha, ni tampoco en torno al sujeto humano, no es ni teocéntrico ni antropocéntrico."

bi-dimensional de su maestro Santo Thomás de Aquino.

La Economía Sacramental de la Salud medieval trata en esencia de la Gracia como valor espiritual supremo, pero aglutina y magnetiza también los otros valores espirituales y los valores materiales, como los valores económicos de los bienes y servicios producidos para el consumo. En cambio, en el concepto andino, la Economía de Crianza de la Vida (ECV) se refiere a los valores económicos concretos que sustentan la vida y la supervivencia, idealizada en la Sumaq Kawsay (la vida dulce y armoniosa), pero siempre se tiene en cuenta su apreciación mitológico-religiosa, o sea su valor metaeconómico, lo que resulta en un concepto religioso del trabajo como 'celebración de la Vida', y una ética del trabajo normada por la 'conciencia natural' y el respeto absoluto a la ecología del medio natural.

Cuando Schillebeeckx habla de la Economía Sacramental de la Salud no considera en ningún momento la economía de valores materiales de mercado. Por lo demás, la ESS no es una economía cuantitativa; imposible pensar aquí en una contabilidad cuantitativa de Gracia (valor) y Culpa (deuda), sino que es eminentemente cualitativa. En esto coincide también con la economía andina de la crianza, que persigue el brillo de la Chacra y la vigorización de la Vida. Por su parte, el cristiano tradicional, igual que el empresario moderno y el técnico, están dispuestos a sacrificar la vida natural, para los 'bienes celestiales', c.q. para 'el progreso'. Por otra parte, el Progreso pareciera ser el justificativo aducido por el hombre moderno, cuando se recuerda el encargo definido por el mito bíblico ${ }^{19} \mathrm{del}$ origen de 'cultivar y cuidar el jardín' (Gn 2: 15) y cuando sospecha que es responsable de la abominación ecológica: 'Ahora la tierra va a estar bajo maldición por tu culpa' (Gn 3: 17).

Para el andino y la andina tradicional, 'cristiano/a a su manera', el mito de la Biblia es muy claro sobre la Vida y la Muerte, el Hombre y la Tierra. El runa reconoce en esas palabras la confirmación de su Pacha-vivencia y su ética tradicional: el origen del Hombre: 'formado de la tierra' y su castigo: 'en tierra te convertirás'; sobre el encargo de 'cuidar el jardín'; sobre la consecuencia del pecado: 'por tu culpa

19 Ver 8. "Anexo: Textos bíblicos del mito del origen". 
la tierra estará bajo maldición'. El runa entiende el pecado continuado contra la Vida y comprende sus consecuencias: la muerte del pecador y la maldición de la tierra (entendida como el agotamiento de la Pachamama). Pero le duele que el misionero y el colonizador contemporáneos siguen despreciando el fruto del árbol de la Vida y comiéndose el fruto de la Muerte y de la Maldición ecológica. Porque haciendo memoria y mirando su ayllu, concluye que por ellos cada vez más éste se aleja del Sumaq Kawsay.

\section{Anexo: Citas bíblicas del mito del origen}

(las negrillas son nuestras)

- Génesis 2: 4-9 (Edén y el Árbol de la Vida): "4 Cuando Dios el Señor hizo el cielo y la tierra, 5 aún no había plantas ni había brotado la hierba, porque

Dios el Señor todavía no había hecho a nadie que la trabajara. 6 Sin embargo, de la tierra salía agua que regaba todo el terreno. 7 Entonces Dios el Señor formó al hombre de la tierra misma, y sopló en su nariz y le dio vida. Así el hombre comenzó a vivir. 8 Después Dios el Señor plantó un jardín en la región de Edén, en el oriente, y puso allí al hombre que había formado. 9 Hizo crecer también toda clase de árboles hermosos que daban fruto bueno para comer. En medio del jardín puso también el árbol de la vida y el árbol del conocimiento del bien y del mal."

- Génesis 2: 10-15 (para cuidar el jardín): “10 En Edén nacía un río que regaba el jardín, y que de allí se dividía en cuatro. 11 El primero se llamaba Pisón, que es el que da vuelta por toda la región de Havila, donde hay oro. $12 \mathrm{El}$ oro de esa región es fino, y también hay resina fina y piedra de ónice. 13 El segundo río se llamaba Gihón, y es el que da vuelta por toda la región de Cus. 14 El tercero era el río Hidekel, que es el que pasa al oriente de Asiria. Y el cuarto era el río Eufrates. 15 Dios el Señor puso al hombre en el jardín de Edén para que lo cultivara y lo cuidara."

- Génesis 3: 16-19 (Adán y Eva desobedecen a Dios y lo pierden todo): "16 A la mujer le dijo: (porque hiciste esto,) aumentaré tus dolores cuando tengas hijos, y con dolor los darás a luz. Pero tu deseo te llevará a tu marido, y él tendrá autoridad sobre ti. $17 \mathrm{Al}$ hombre le dijo: - Como le hiciste caso a tu mujer y comiste del fruto del árbol del que te dije que no comieras, ahora la tierra va a estar bajo maldición por tu culpa; con duro trabajo la harás producir tu alimento durante toda tu vida. 18 La tierra te dará espinos y cardos, y tendrás que comer plantas silvestres. $19 \mathrm{Te}$ ganarás el pan con el sudor de tu frente, hasta que vuelvas a la misma tierra de la cual fuiste formado, pues tierra eres y en tierra te convertirás."

- Génesis 3: 23s. (La Vida cortada): “23 Por eso Dios el Señor sacó el hombre del jardín de Edén, y lo puso a trabajar la tierra de la cual había sido formado. 24

Después de haber sacado al hombre, puso al oriente del jardín unos seres alados y una espada ardiendo que daba vueltas hacia todos lados, para evitar que alguen llegara al árbolde la vida."

\footnotetext{
REFERENCIAS

-Armstrong, Karin (2001) Holy War; The cruzades and their impact on today's world; Anchor Books, New York.

-Burns, Kathryn (1999) Colonial habits: Convents and
} 
the spiritual economy of Cuzco, Perú. Londres: Duke University.

-Estermann, José (1997) Elementos para la reivindicación del pensamiento colonizado. En: Cuadernos IECTA N¹2:"Filosofía Andina".Iquique: IECTA.

-Estermann, José (2006) Filosofia Andina: Sabiduría indigena para un mundo nuevo. La Paz: ISEAT

-Kessel, Juan van \& Condori Cruz, Dionisio (1992) Criar la vida: trabajo y tecnología en el mundo andino. Santiago - Chile, Vivarium.

-Schillebeeckx, Edward (1952) Christus en Zijn sacramentele genadebemiddeling [Cristo y su medianía sacramental de la gracia]. En: Obras.

-Schillebeeckx, Edward (1959) Christus: Het sacrament van de Godsontmoeting [Cristo, el sacramento del encuentro con Dios]. Bilthoven: Verbum.

—Tomás de Aquino (1274/1888ss.): Summa Theologiae. [Edición Leonida]. Roma: Textum Leoninum. 